\title{
Fatal infections in protein-calorie malnourished children with thymolymphatic atrophy
}

\author{
DAVID T. PURTILO and DANIEL H. CONNOR \\ From the Infectious Disease Branch, and the Geographic Pathology Division, Armed Forces Institute of \\ Pathology, Washington, D.C.
}

\begin{abstract}
Purtilo, D. T., and Connor, D. H. (1975). Archives of Disease in Childhood, 50, 149. Fatal infections in protein-calorie malnourished children with thymolymphatic atrophy. The clinicopathological features of 25 children who died with protein-calorie malnutrition were studied. All but four subjects were found at necropsy to have nutritional thymectomy and all but 3 died of infectious diseases. The infectious agents were chiefly intracellular micro-organisms including miliary tuberculosis, Herpes simplex, varicella, measles, Pneumocystis carinii, and Plasmodium falciparum. Staphylococcal infections, salmonellosis, shigellosis, strongyloidiasis, and hookworm were other significant infectious agents. Nutritionally acquired defective immunity, especially cell-mediated immunity, probably permitted these infectious agents to multiply and to disseminate widely.
\end{abstract}

Malnutrition predisposes children to infections by producing defective epithelial barriers, granulocytic dysfunction, and impaired immunity (Smythe et al., 1971; McFarlane, 1971). It is not surprising, therefore, that children with marasmus or kwashiorkor die of infections (Gordon and Scrimshaw, 1970). Kwashiorkor, a syndrome afflicting young children, results from a deficiency of protein, and marasmus arises from a deprivation of protein and calories and is distinguished from kwashiorkor by the absence of oedema (Ogbeide, 1971; Trowell, - Davies, and Dean, 1954).

All 25 of the children from the Geographic Pathology Registry of the Armed Forces Institute of Pathology (AFIP) with protein-calorie malnutrition (PCM) who died and had necropsy performed form the basis of this study. Atrophy of their thymus glands and thymus-dependent areas in their lymph nodes and spleen were found. Atrophy of the thymolymphatic system may be a morphological manifestation of defective cell-mediated immunity. Acquired defects in immunity in our subjects probably permitted the severe infections described herein to lead to the death of 22 of the 25 subjects suffering from PCM.

\section{Materials}

We analysed the dietary history, results of the physical examination, and laboratory findings from the

Received 7 June 1974. clinical records and necropsy reports of all 25 children with PCM on file in the Registry of Geographic Pathology at the AFIP. 11 had kwashiorkor and all but one were from Uganda. The other 14 subjects had marasmus: 3 each were from the United States, Brazil, and the Philippines, 2 from the Republic of Zaire, and one each from New Guinea, Panama, and Uganda. Gross and microscopical evaluation of thymus, spleen, mesenteric lymph nodes, tonsils, appendix and ileum, liver, pancreas, and other organs was done. We related the degree of atrophy of the thymolymphatic system with the inflammatory response to the infections.

\section{Results}

A typical infant dying of kwashiorkor manifested a complex of oedema, sparse red-brown hair, hypopigmented skin, dermatitis, and apathetic facies. The diet of the Uganda children dying of kwashiorkor consisted chiefiy of matoke and tomatoes. Insects were frequently the only source of protein. All but one of our 25 subjects with PCM were below the 3rd centile on the Boston standard (Stuart and Meredith, 1946) and compared to well-nourished Ugandan children (Brown, 1965), were also significantly undersized for their ages (range 3 to 84 months; mean 29 months). There were 13 males and 12 females, 17 blacks, 3 whites, and 5 of mixed races.

Infections. 22 patients died of devasting infectious diseases including 4 with disseminated 
varicella, 5 with extensive staphylococcal infections. 3 with anergic miliary tuberculosis, 2 of hyperinfections by Strongyloides stercoralis, 2 with cerebral malaria, and 1 each with measles, Herpes simplex, Pneumocystis carinii, diphtheria, salmonellosis, shigellosis (Table), and 20 of the patients had

\section{TABLE}

Fatal infections in 23 children with protein-calorie malnutrition

\begin{tabular}{l|l} 
Malaria & 2 \\
Staph. aureus & 2 \\
M. tuberculosis & 3 \\
Strongyloides stercoralis & 2 \\
Salmonella group B & 1 \\
Shigella flexneri & 1 \\
Pneumocystis carinii & 1 \\
Varicella & 4 \\
Measles & 1 \\
Herpes simplex & 1 \\
Diphtheria & 1 \\
\end{tabular}

two or more significant infections. Other infections contributing to the death of our patients with PCM included intensive nematode infections and acute bronchopneumonia.

One 4-year-old boy dying of Herpes simplex infection had severe kwashiorkor and lesions caused by Herpes simplex in his gastrointestinal tract, liver, lungs, adrenals, and brain. An 11-month-old Ugandan with marasmus died of measles giant-cell pneumonia. He had Warthin-Finkeldy cells in his appendix and lymph nodes and nearly total lymphocyte depletion of his splenic, thymus-dependent periarteriolar lymphoid sheaths. 5 other children had had measles within 3 months preceeding their admission to the hospital. 3 children from the United States with persistent diarrhoea and vomiting developed marasmus and succumbed to disseminated varicella.

Two with marasmus died of cerebral malaria. Their cerebral capillaries were choked with parasitized erythrocytes, and ring haemorrhages were present. We found abundant malarial pigment in reticuloendothelial cells of the liver, spleen, lymph nodes, and bone marrow in 10 of our subjects and lesser amounts in 4 other subjects. 5 subjects examined ante mortem for malaria had circulating $P$. falciparum parasites.

Three infants died of miliary $M$. tuberculosis. Their lymph modes were depleted of lymphocytes and they lacked Langhans's giant cells in caseating lesions. 6 children died with extensive acute bronchopneumonia including 3 with extensive staphylococcal bronchopneumonia. A patient with measles and 2 patients with varicella pneumonia had superimposed staphylococcal pneumonias. One girl had staphylococci in her cerebrum and 2 other children had large cutaneous ulcers. 2 died of disseminated Staph. aureus abscesses. In total, at least 5 children died with staphylococcal infections.

Two subjects died with marked anaemia and Necator americanus infections. Their stool egg counts were $14500 \mathrm{eggs} / \mathrm{g}$ and $7500 \mathrm{eggs} / \mathrm{g}$, respectively. Strongyloides stercoralis larvae were found in stools from 3 subjects who had ulcerated gastrointestinal tracts and 2 had filariform larvae deep within their colon walls and livers, characteristic of hyperinfection. These 2 children were recently reported by us in a series of 32 patients dying with hyperinfection who were variously immunosuppressed by PCM, various metabolic states, malignancy, prednisone, and other lymphocytotoxic drugs (Purtilo, Meyers and Connor, 1974). Ascaris lumbricoides infection was gross in one patient and mild in 2.

Thymolymphatic organs. The thymus glands were atrophic except for 3 from infants with marasmus and one from a child with kwashiorkor. The thymus glands ranged in weight from 2.5 to $28 \mathrm{~g}$ and averaged $5 \mathrm{~g}$. A loss of corticomedullary demarcation, a relative increase in fibrovascular tissues, and marked depletion of lymphocytes was found in most of the thymus glands. Hassall's corpuscles were frequently dilated.

Depletion of lymphocytes in the paracortical, thymus-dependent regions of lymph nodes was marked in 9 subjects, moderate in 5, slight in 6 , and absent in 5 subjects. The severest lymphoid depletion occurred in patients with ante-mortem lymphopenia and more commonly in patients with kwashiorkor than those with marasmus. Active germinal centres were present in only 4 subjects, but plasma cells were present in all of the lymph nodes.

The spleens weighed an average of $\mathbf{4 2} \mathrm{g}$ compared to an average of $32 \mathrm{~g}$ for well-nourished children of comparable ages previously reported (Mugerwa, 1971). The thymus-dependent, periarteriolar lymphocytic sheaths were depleted of lymphocytes in approximately one-half of the subjects. Prominent depletion of lymphocytes was found in the infant dying of measles. Germinal centre activity was decreased or absent in all but 3 of the spleens examined. Most of the sinuses were distended with erythrocytes and those infected by malaria contained abundant malarial pigment.

The bone marrows were normocellular or hypercellular except for one. Normoblastic hyperplasia generally accounted for most of the hypercellularity of the marrows, but the myeloid component also 
was frequently hyperplastic. One-third of the marrows contained no stainable iron. Plasma cells and lymphocytes were present in all marrows.

The other lymphoid organs, the tonsils, vermiform appendices, and Peyer's patches of the ileum were generally depleted of lymphocytes and germinal centres were small or absent.

The livers varied in their fat content from mild peripheral lobular fat in subjects with marasmus to extensive panlobular fatty metamorphosis in those with kwashiorkor. The pancreas glands were atrophic and the acinar cells were depleted of zymogen granules in all 25 of the subjects.

\section{Discussion}

Cell-mediated immunity is a bulwark against certain intracellular micro-organisms including viruses, fungi, protozoans, and metazoans (Valentine and Lawrence, 1971). The results of the present study confirm Smythe et al. (1971) and Mugerwa's (1971) reports that thymolymphatic atrophy occurs in children with PCM.

Infections may precipitate kwashiorkor in infants having diets deficient in protein. Measles, for instance, is an infection that frequently pushes malnourished infants into frank kwashiorkor (Gordon and Scrimshaw, 1970; Smythe et al., 1971). 5 of our subjects had measles preceding the onset of their PCM and one child with marasmus died of measles pneumonia. Measles with fatal giant-cell pneumonitis in children with PCM is strikingly similar to the nonexanthematous, giantcell measles occurring in patients with acute leukaemia receiving steroid therapy. Burnet (1968) proposed that giant-cell measles occurs because of a deficiency in cell-mediated immunity (CMI).

CMI protects against intracellular micro-organisms. The 14 subjects infected with malaria lived in endemic areas. Both of the deaths due to cerebral malaria occurred in children with marasmus. Evidence is building that cellular immunity is important in checking malarial infections (Osunkoya, Williams, and Reddy, 1972). Defective CMI may permit $P$. falciparum to proliferate and to kill the host.

Pneumocystis carinii and Herpes simplex are 'opportunistic' organisms infecting immunosuppressed patients. Herpes simplex has a high degree of pathogenicity, but normally low virulence. Templeton (1970) described 6 Ugandan children dying of generalized Herpes simplex: 5 had kwashiorkor and the other was a neonate. Depressed CMI in children with PCM probably permits dissemination of Herpes simplex. As with measles, Herpes simplex occurring in patients having depressed
CMI caused by malignancies and chemotherapy is frequently lethal (Burnet, 1968).

Our 4 infants dying of varicella are among 21 cases of varicella at the AFIP during the years 1940 through 1964 (Strano, 1968). 9 of the 21 subjects had immunosuppression caused by malnutrition, malignancies, pregnancy, or debilitating diseases.

Miliary tuberculosis killed 3 of our subjects with PCM. Protein may be required to provide cellular immunity against tuberculosis. Tuberculosis in a non-meat-eating East African tribe occurs at a $6 \%$ frequency as compared to a $1 \%$ frequency in a nearby meat-eating tribe (Mayer, 1971). Depressed CMI in malnourished children with active tuberculosis is manifested by their markedly decreased lymphocyte transformation response to stimulation with phytohaemagglutinin or to intracutaneous tuberculin challenge (Lloyd, 1968; Smythe et al., 1971). Our 3 patients with tuberculosis had inadequate CMI response to $M$. tuberculosis or the anergic form of tuberculosis.

Deaths caused by staphylococci in at least 2 subjects shows that staphylococci is an important infectious agent in patients with PCM. Dogma asserts immunoglobulins protect against pyogenic bacteria, but recently Mudd, Taubler, and Baker, (1970) challenged this concept. They suggest Staph. aureus becomes a facultative intracellular parasite and delayed hypersensitivity to Staph. aureus may thus be important in the control of Staph. aureus.

A loss of the bacteriostatic effect due to depletion of transferrin in the serum of patients with kwashiorkor may further explain increased susceptibility to Staph. aureus (McFarlane, Okubadejo, and Reddy, 1972). Cell-mediated immunity, immunoglobulins, and transferrin are possibly protective against staphylococcal infections, but may be deficient in patients with PCM. Serum immunoglobulins and transferrin are possibly protective against staphylococcal infections but may be deficient in patients with PCM. Serum immunoglobulins have been shown to be increased in concentration in infected children with PCM (Rosen and Geefhuysen, 1971). The hyper- $\gamma$-globulinaemia occurring in parasitized malnourished children may result from a preponderance of B-lymphocytes along with concurrent depletion of T-lymphocytes associated with nutritional thymectomy (Purtilo et al., 1975).

Deaths among our patients due to Gram-negative bacteria, Esch. coli, salmonella group B, and Shigella flexneri, may have been due to lower serum complement levels. 8 of 9 components of complement have been found to be depressed in children with 
PCM and complement is considered vital in checking Gram-negative infections (Sirisinha et al., 1973).

Nutritional thymectomy occurred in the majority of our PCM patients. Findings substantiating this claim include our demonstration of significant atrophy of the thymus and depletion of the thymusdependent lymphocytes in the patients' lymph nodes and spleens. Our findings in the lymphoid tissues were strikingly similar to those reported in neonatally thymectomized aniamls (Heim, Yunis, and Good, 1972).

Also the intracellular micro-organisms that killed our patients are normally controlled by CMI. Hence, our demonstration of thymolymphatic atrophy and the associated infections suggest to us why infants with PCM frequently die of infectious diseases.

The reasons for defective CMI in PCM are obscure. Lymphopenia and thymolymphatic atrophy may result from lymphocytolysis due to the lytic effect of free 11-hydroxycorticosteroid in the plasma of patients with PCM (McFarlane, 1971). Inability to synthesize corticosteroid binding protein could result in an increase in the free active form of 11-hydroxycorticosteroid. Deficient dietary amino acids could impair synthesis of proteins required for lymphopoiesis, produce thymolymphatic atrophy and defective CMI in children with PCM.

The sequence of events occurring in PCM is unclear since thymolymphatic atrophy and infectious diseases generally occur simultaneously. But the report of depressed CMI in noninfected children with PCM is compelling evidence that thymolymphatic atrophy precedes the infections (Smythe et al., 1971). Hence the infections occurring in our patients with PCM probably resulted chiefly from nutritional thymectomy and depressed CMI, but other immunological defense mechanisms were also probably impaired.

\section{REFERENCES}

Brown, R. E. (1965). Decreased brain weight in malnutrition and its implications. East African Medical fournal, 42, 584.

Burnet, F. M. (1968). Measles as an index of immunological function. Lancet, 2, 610.
Gordon, J. E., and Scrimshaw, N. S. (1970). Infectious diseases in the malnourished. Medical Clinics of North America, 54, 1495.

Heim, L. R., Yunis, E. J., and Good, R. A. (1972). Pathogenesis of graft-versus-host reaction. International Archives of Allergy, 42, 565.

Lloyd, A. V. C. (1968). Tuberculin test in children with malnutrition. British Medical fournal, 3, 529.

McFarlane, H. (1971). Cell-mediated immunity in protein-calorie malnutrition. Lancet, 2, 1146.

McFarlane, H., Okubadejo, M., and Reddy, S. (1972). Transferrin and Staphyloccocus aureus in kwashiorkor. American fournal of Clinical Pathology, 57, 587.

Mayer, J. (1971). Nutrition and tuberculosis. Postgraduate Medicine, 50, 53.

Mudd, S., Taubler, J. H., and Baker A. G. (1970). Delayed-type hypersensitivity to Staphylococcus aureus in human subjects. Fournal of the Reticuloendothelial Society 8, 493.

Mugerwa, J. W. (1971). The lymphoreticular system in kwashiorkor. Fournal of Pathology, 105, 105.

Ogbeide, M. I. (1971). The clinical pattern of protein-calorie malnutrition in Ibadan, Nigeria. West African Medical Fournal, 20, 313.

Osunkoya, B. O., Williams, A. I. O., Reddy, S. (1972). Spontaneous lymphocyte transformation in leucocyte cultures of children with Falciparum malaria. Tropical and Geographical Medicine, 24, 157.

Purtilo, D. T., Meyers, W. M., and Connor, D. H. (1974). Fatal strongyloidiasis in immunosuppressed patients. American Fournal of Medicine, 56, 488.

Purtilo, D. T., Riggs, R., Evans, R., and Neafie, R. (1975). Humoral immunity in parasitized malnourished children. (Submitted for publication.)

Rosen, E. U., and Geefhuysen, J. (1971). Immunoglobulin levels in protein-calorie malnutrition. South African Medical fournal, 45,980 .

Sirisinha, S., Suskind, R. Edelman, R., Charupatana C., and Olson, R. E. (1973). Complement and C3-proactivator levels in children with protein-calorie malnutrition and effect of dietary treatment. Lancet, 1, 1016.

Smythe, P. M., Schonland, M., Brereton-Stiles, G. G., Coovadia, H. M., Grace, H. J., Loening, W. E. K., Mafoyane, A., Parent, M. A., and Vos, G. H. (1971). Thymolymphatic deficiency and depression of cell-mediated immunity in protein-caloric malnutrition. Lancet, $2,939$.

Strano, A. J. (1968). Generalized varicella. Armed Forces Institute of Pathology Clinical Pathological Conference, nos. 10-68, p. 1. American Registry of Pathology, Washington, D.C.

Stuart, H. C., and Meredith, H. V. (1946). Use of body measurements in the school health program. American fournal of Public Health, 36, 1365.

Templeton, A. C. (1970). Generalized herpes simplex in malnourished children. Fournal of Clinical Pathology, 23, 24.

Trowell, H. C., Davies, J. N. P., and Dean, R. F. A. (1954). Kwashiorkor, p. 69. Arnold, London.

Valentine, F. T., and I.awrence, H. S. (1971). Cell-mediated immunity. Advances in Internal Medicine, 17, 51.

Correspondence to Dr. D. T. Purtilo, Department of Pathology, University of Massachusetts Medical School, 55 Lake Avenue North, Worcester, Mass. 01605, U.S.A. 